\title{
Technology of plant raw material production with high-ratio selenium for food products manufacturing
}

\author{
Larisa Mayurnikova*, Tatyana Krapiva, Mikhail Kurakin, Arkadiy Koksharov, and Dina Shalimova
}

Kemerovo State University, 650056 Krasnaya 6, Russia

\begin{abstract}
The food-borne micronutrient deficiency causes diet-related diseases. The problem is part of great challenges and demands a solution. The human body is the most vulnerable to selenium deficiency. The physiological requirement in this micronutrient is, in one respect, small - $70 \mathrm{mg}$ per day, on the other hand, it causes a number of serious diseases. The experience was obtained of providing the population with micronutrients. It is possible to include biologically active supplements, vitamin and mineral preparations (VMP) into the ration, direct micronutrient supplementation into food products at the production stage, fortification of animal feedstuff, etc. Fortification of plant raw material with selenium during the growing stage was studied. Further, the fortified plant raw material is supposed to be used in prophylactic food products manufacturing. The most common plants with high biologically active substance (BAS) content, including selenium were chosen. They are certified and widely used in pharmacology and food industry. The most prospective concentrator agent is sweet-clover. The fortification technology for hydroponically grown sweet-clover was carried out in laboratory. Growing of the plant was carried out on hydroponics by putting it into the natural environment system. For achieving the optimum the following factors were varied: the content and concentration of the medium; the concentration of selenium preparation; temperature, humidity and dormancy period of the plant. It was established that the plant consumes selenium well in combination with the definite set of biologically active substances from the medium. As compared to the original selenium content $(0.312 \mathrm{mg} / \mathrm{kg}$ of dry raw material) its quantity reached $3.50 \pm 0.80 \mathrm{mg} / \mathrm{kg}$ after fortification. Total selenium content in sweet-clover may be forecast with allowances for the preset parameters. It is advisory to continue the research on adapting the plant fortification technology using selenium preparations on commercial scale. The allowances should be made for climatic conditions, supplementation method, strength of the solutions, growth environment.
\end{abstract}

\section{Introduction}

The selenium demand for the body was first established in 1957 during the experimental research on rats showing that it was that element that inhibits liver apobiosis in rats [1]. The role of selenium in human pathology was revealed while describing selenium deficiency cardiomyopathy in China (Keshan disease) [2].

Lack of selenium in soil as geochemical feature is characteristic of various regions in Russia, Republic of Belarus, Finland, Baltic sates and a number of other countries.

In Russia, ultra-low selenium levels in soils, water and food products are recorded in the Chechen Republic, Chitinskaya and Irkutskaya regions, in the Khabarovsk territory $[3,4,5,6,7]$.

On the whole, selenium deficiency is of certain significance for male and female bodies [8]. The results of population assessment in the Kemerovo region indicate selenium deficiency of different severity among about $90-95 \%$ of the population, the value reaching $100 \%$ with women $[9,10]$. The Kemerovo region located in the central part of Russia is the area of goiter endemia, and iodine and selenium deficiencies are known to be overlapping [11]. The combination of these microelement deficiencies can be one of the main risk factors of triggering a number of diseases, first of all, of the endemic goiter. It supports the necessity of selenium status correction among the people living in goiter endemia areas.

Scientists within the country and abroad have shown that selenium is contained in all sites of the human body [12], the amount and distribution of the micro-element depends on the body's selenium status, course of intake and the chemical modification of selenium in the ration [13]. With the selenium deficiency, its inclusion affects the most important proteins and tissues - especially reproductive and endocrine organs, brain. Skeletal muscles and heart are supplied with selenium at a slower rate.

The role of selenium is foremost defined by its inclusion into the composition of one of the primary antioxidant enzymes - Se-dependent glutathione peroxidase, which protects the cells from the accretion of peroxidation products (peroxide lipids, hidrogen

\footnotetext{
* Corresponding author: nir30@mail.ru
} 
peroxide), thus preventing its nuclear and protein synthesis system from disorder [14, 15]. Selenium compounds exhibit significant antioxidant activity (AOA), preventing the cells' membranes from alteration and, consequently, reserve the cells' viability and prevent the diseases mentioned above $[16,17,18]$.

The main ways of elimination of micronutrient deficiency, including that of selenium are:

- including the products with high natural content of the nutrient into the ration [19];

- usage of Se-containing vitamin and mineral complexes and biologically active supplements with selenium;

- application of selenium fortification technologies for food products during the manufacturing stage.

The last-mentioned way is the most accessible. The inorganic salts of selenium - sodium selenites and selenates are used in this method [20]. The experience was obtained of supplementing sodium selenites into the raw goat's milk, and of sodium selenates - into nonalcoholic beverages [22].

Of special interest is the study of the plant raw material fortification method at the growing stage and its succeeding usage in food products manufacturing as the recipe ingredient.

\section{Subjects and methods of research}

Subjects of research: sweet-clover (Melilotus officinalis L.), hydroponics for growing plant raw material, selenium preparations for the fortification of sweetclover at the growing stage.

Experimental study was carried out in several steps. The sweet-clover plant was transferred from natural growth habitat into the laboratory hydroponics environment. The plant was conditioned in hydroponics solutions of different selenium concentrations, the roots were thoroughly washed with distilled water, dried, reduced in size and tested for selenium. Determination of total selenium content was conducted on the automatic three channel voltammetric STA complex with vibrating main electrode using the method of MU $08-47 / 132$ [23].

\section{Results and discussion}

The ability of plants to store micro-elements, in particular, selenium is an important criterion in choosing the plant for fortification. The analysis of scientific literature has shown that, with reference to selenium, there are no definite plant families with the ability to store large quantities of selenium.

Seven plant families with a number of species able to cumulate fair enough amount of selenium were distinguished. Here belong legumes, liliaceous, composite, umbelliferous, rose, mint and ginseng families [24, 25]. Inside every family enumerated, there are plants storing selenium, as well as indifferent to it.

Most selenium cumulating plants are in legumes family (Fabaceae). These are super-cumulators of selenium - astragali (Astragalus bisulcatus, Astragalus crotalariae). They can cumulate large quantities of the micro-element: $1.0 \%$ of the plant biomass, not manifesting any signs of toxicosis. The intake of such plants can lead to severe poisoning. The family includes plants tolerant to fairly high doses of selenium (according to the data - up to tens milligrams per a kilogram of biomass), such as sweet-clover (Melilotus officinalis, Melilotus indica), alfalfa, liquorice, soybean, etc. Their natural selenium content varies from 0.2 to $0.35 \mathrm{mg} / \mathrm{kg}$, though the plants can store up to $10 \mathrm{mg}$ of selenium per a kilogram of biomass under cultivating conditions in the soils with higher level of selenium.

Besides, with selenium concentrations of more than $10 \mathrm{mg} / \mathrm{kg}$ the plant may show the signs of toxicosis, such as slowing down growth and development, and concentrations of more than $20 \mathrm{mg} / \mathrm{kg}$ can cause perishing of the plants. The fact may serve as a specific indicator of ultra-high amount of selenium in the plant, and give warning about the doses dangerous for man [26].

This feature is also characteristic of the umbelliferous (Umbrelliferae): parsnip, parsley, dill, coriander, fennel; composite or sunflower family (Asteraceae): sagebrush, holy thistle, camomile, foalfoot, milfoil, burdock, tansy; dead nettles or lip-flowered (Lamiaceae): mint, thyme, sage; liliaceous (Liliaceae): aloe, onion, garlic; rose family: European meadowsweet; and also ginseng family (Araliaceae). Other families contain from one to two representatives able to cumulate some amount of selenium. To them belong the pinaceous (Siberian larch), and also the birch, erica, buckwheat, hypericaceae, hemp, nettle, schisandraceae, papaveraceous, myrtle, solanaceous, orpine, horsetail and tea families.

The selenium content in plants belonging to $\mathrm{Se}$ cumulating families was investigated. The results of the research are presented in Table 1.

Table 1. Selenium content in medicinal plant raw material (calculated as absolute dry raw material).

\begin{tabular}{|c|l|l|l|l|}
\hline $\begin{array}{c}\text { Descript } \\
\text { ors }\end{array}$ & $\begin{array}{l}\text { Siberian } \\
\text { larch }\end{array}$ & $\begin{array}{c}\text { Silky } \\
\text { wormwo } \\
\text { od }\end{array}$ & $\begin{array}{c}\text { Pepper } \\
\text { mint }\end{array}$ & $\begin{array}{c}\text { Sweet- } \\
\text { clover }\end{array}$ \\
\hline $\begin{array}{c}\text { Selenium } \\
\text { content } \\
\text { (total), } \\
\mathrm{mg} / \mathrm{kg}\end{array}$ & $0.180 \pm 0$. & $0.125 \pm 0$. & $0.021 \pm 0$. & $0.312 \pm 0$. \\
006 & 038 & 093 \\
\hline
\end{tabular}

From the list of the plants under analysis, sweetclover has most selenium content $(0.312 \mathrm{mg} / \mathrm{kg}$ of dry matter), that proved the plant's ability to cumulate selenium.

Sweet-clover can be referred to as the so-called uncustomary selenium concentrator due to its ability to cumulate the micro-element. The plants belonging to this group can store up to a few milligrams of selenium per a kilogram of plant biomass.

The research experience shows that plants are usually fortified with preparations containing sodium selenites or sodium selenates, the latter being faster assimilated by the plants, as compared to selenite. However, while analyzing the chemical composition of raw material fortified with sodium selenates, it was discovered that 
most selenium found in the plant is due to this compound.

This points to the fact that sodium selenate is chemically inert for plants. Moreover, being perorally or parenterally introduced into the human body, it is excreted with urine, actually having no biological functions. This counts in favor of sodium selenite and was the substantiation for choosing it as the fortifying supplement.

The research aimed at uncovering the maximum selenium concentration which sweet-clover can store, was carried out using the method of hydroponic culture [27]. The researchers made use of whole blooming plants of sweet-clover, gathered from the two kinds of soil: clay and rocky, in the middle of July, before noon in dry sunny weather at the air temperature of $25-28^{\circ} \mathrm{C}$. The sweet-clover was bodily dug out without damaging of its root. The plants from the rocky soil reached 100 $\mathrm{cm}$ height and more, had fairly developed texture: thick rough culm with many side branches, ramous root system. Sweet-clover samples taken out of the clay soil reached $70 \mathrm{~cm}$ height, had a slim culm, less developed, subramous root. Apart from the plants, samples from the soil types were collected for selenium content analysis.

Samples parameter datum for the plants dependent on the type of soil they were taken from is presented in Table 2.

Table 2. Samples parameters of sweet-clover.

\begin{tabular}{|l|c|c|}
\hline \multirow{2}{*}{ Plant characteristics } & \multicolumn{2}{c|}{ Type of soil } \\
\cline { 2 - 3 } & Rocky & Clay \\
\hline Average length of a plant, cm & $100-102$ & $40-86$ \\
\hline Average length of roots, cm & $15-17$ & $11-14$ \\
\hline
\end{tabular}

It is shown that the plants taken from the clay soil are characterized by smaller size in comparison with those from the rocky soil, the roots of the former being less branched and less developed.

The selenium content in plants grown on different types of soils was studied (table 3 ). The sweet-clover collected from the clay type soil has a higher selenium content than the plant from the rocky soil. As the plants from the clay soil were characterized by far less size of the root and culm (length, thickness, branchiness) as compared with those from the rocky soil, the conclusion can be drawn that size is not the critical factor in the cumulation of selenium.

Table 3. General selenium content in sweet-clover* grown in different soils $(\mathrm{n}=3, \mathrm{P}=0.95)$.

\begin{tabular}{|c|c|}
\hline Type of soil & Se content, $\mathbf{~ m g} / \mathbf{k g}$ \\
\hline rocky & $0.25 \pm 0.06$ \\
\hline clay & $0.31 \pm 0.08$ \\
\hline $\begin{array}{l}\text { Notes: * The dry grass mixture fine-cut to powdery state } \\
\text { was under analysis. }\end{array}$ \\
\hline
\end{tabular}

The results obtained differ from the opinion about the developed root system of the plants cumulating selenium. In the given case, probably, it is connected with the specific qualities of the soil types.

With the purpose of adaptation to new environment the plants were conditioned in tap water during three days with subsequent transplanting into the hydroponic solution. To create conditions, which are the closest to natural environment, $250-500 \mathrm{~cm}^{3}$ containers one quarter in blackout material were used. By reference to the plants' dimension, the variables were: plants' size, liquid volumes and nutritive medium: the hydroponic system of plants of $40 \mathrm{~cm}$ length contained $30 \mathrm{~cm}^{3}$ of solution; others contained $50 \mathrm{~cm}^{3}$.

As a nutritive solution the Knop's mixture of elements was used [28]. Two milliliters of microelement solution of copper sulphate, boracic acid, stannic chloride (divalent), iodic potassium, and zinc sulfate (heptahydrate) were added to the ready-mixed Knop's solution for better development of the plant.

Before immersion into the nutritive solution the plants' roots were thoroughly washed with distilled water. For the root system oxygen supply the roots were fastened in such a way that one third of the roots were only immersed into the liquid, and two thirds of them were in the open air. The research was done under the following conditions: average temperature $-25^{\circ} \mathrm{C}$, relative air humidity $-70-75 \%$; the artificial lighting was not used.

In three days sodium selenite was introduced into every hydroponic system in concentrations: $0.4 ; 1.2 ; 4.0$ and $5.0 \mathrm{mg} \mathrm{Se} / \mathrm{dm}^{3}$. The period of the plants conditioning in solutions containing selenium was 8 days, during which changes taking place in the plants were watched. In the experimental process the plants in the solutions of 4.0 and $5.0 \mathrm{Se} \mathrm{mg} / \mathrm{dm}^{3}$ demonstrated rapid growth suppression, which was exhibited by serious drying up, partial defoliation and loss of bloom, reddening of roots. The changes are, probably, physiological and biochemical reactions to the new conditions, and may be also caused by partial distortion of breathing and feeding of the plants due to the reduction of $\mathrm{Se} 4$ to $\mathrm{Se}$ in the solution and the adsorption of the latter on the root surface.

On finishing the conditioning process of the plants in the nutritive medium with different concentrations of selenium the roots were thoroughly washed with distilled water. Then the whole plants underwent drying at room temperature during 10 days, at a temperature of $35^{\circ} \mathrm{C}$ during 3 days - with the purpose of defining the optimum parameters for the drying of Se-fortified plant raw material (for its subsequent storage). Drying at higher temperatures is not practicable, as the temperatures higher than $40^{\circ} \mathrm{C}$ can lead to significant loss of the micro-element due to the formation of volatile compounds. The alternative is storage of just harvested, slightly cut raw material (or fine-cut paste-like) in the frozen state. Though in melting the worsening of the raw material organoleptic properties, and also the loss of biologically active substances with cell juice can occur, which is not desirable in this case.

Selenium content in the mixture of the above-ground part of the nutritionally conditioned sweet-clover with different selenium concentrations is presented in Table 4. 
Table 4. Selenium content in the sweet-clover* nutritionally conditioned with different concentrations of sodium selenites, $(\mathrm{n}=3, \mathrm{P}=0.95)$.

\begin{tabular}{|c|c|c|}
\hline № & $\begin{array}{c}\text { Selenium introduced } \\
\text { into the solution, } \mathbf{~ m g} / \mathbf{l}\end{array}$ & $\begin{array}{c}\text { Total selenium in a } \\
\text { plant, } \mathbf{~ m g} / \mathbf{k g}\end{array}$ \\
\hline 1 & 0.0 & $0.24 \pm 0.06$ \\
\hline 2 & 0.4 & $0.27 \pm 0.07$ \\
\hline $\mathbf{3}$ & $\mathbf{1 . 2}$ & $\mathbf{3 . 5 0} \pm \mathbf{0 . 8 0}$ \\
\hline 4 & 4.0 & $4.60 \pm 0.80$ \\
\hline 5 & 5.0 & $4.80 \pm 0.90$ \\
\hline \multicolumn{2}{|c|}{$\begin{array}{l}\text { Notes: * For the analysis the dried cut above-ground part } \\
\text { of the plant was used. }\end{array}$} \\
\hline
\end{tabular}

The analysis of the plant samples fortified with selenium with the concentration $4 \mathrm{mkg} / \mathrm{dm}^{3}$ of the nutritive solution and dried under different conditions has shown that at a temperature of $35^{\circ} \mathrm{C}$ and the duration of 3 days the mass concentration of selenium was $6.4 \mathrm{mg} / \mathrm{kg}$ of dry raw material. The plants that had been dried at room temperature (on average about $25^{\circ} \mathrm{C}$ ) during 10 days contained $4.6 \mathrm{mg} / \mathrm{kg}$ of selenium. The results witness the loss of selenium (up to $20 \%$ ) due to prolonged drying, and suggest the practicability of reducing the duration of the process by using the forced drying of raw material with rising the temperature up to $35^{\circ} \mathrm{C}$.

As can be seen from the above, the results of the experimental research proved the hypothesis of the sweet-clover ability to absorb and cumulate selenium. It is shown that there is positive correlation between selenium content in plants and the concentrations introduced into the solution.

Maximum selenium concentration in the plant obtained from conditioning it in the nutritive solution $3.5 \mathrm{mg} / \mathrm{kg}$ of the dry mass that corresponds to the dose of $1.2 \mathrm{mg} / \mathrm{dm}^{3}$ introduced into the plant.

\section{Conclusion}

The use of plant raw material in manufacturing food products of different homogeneous groups, especially of nonalcoholic beverages is prospective and can become part of preventive measures aimed at the population health improvement. Application of the food product fortification technology by adding fortifying supplements at the plant growing stage allows heighten the safety of the enriched product consumption from the point of view of micronutrient dosage and assimilability. The plant as a living organism can regulate the assimilation of doses and forms (organic /nonorganic) of the fortifying supplements. This is timely for $\mathrm{Se}$ micronutrient, the physiological demand of which is $70 \mathrm{mg}$ a day, but its deficiency leads to a number of serious diseases.

The analysis of the scientific literature identified a set of plants - concentrators of selenium, of which the most prospective is the sweet-clover.

The regimes and parameters of selenium fortification technology for the sweet-clover as sodium selenite preparations on hydroponics are developed, allowing obtain plant raw material with preset amount of the micronutrient. For its further use in manufacturing food products (storage) it is recommended to apply the technology of drying at the temperature of $25-35^{\circ} \mathrm{C}$ which is not prolonged in time and promotes maximum reservation of selenium in the raw material.

It is recommended to adapt the developed technology of plant fortification with selenium preparations on the commercial scale, taking into account the climatic conditions, the method of introduction, concentration of solutions, cultivating conditions.

\section{References}

[1] K. Schwars, C.M. Folts,J. Amer. Chem. Soc., 79, 32-92 (1957).

[2] G. Yang, Zh. Chen, et al. Advance in nutritional research, 6, 203-231 (1984).

[3] Z.A. Amagova, N.A. Golubkina, Micro-elements in medicine, 3, 13-19 (2017).

[4] N.A. Golubkina, Z.A. Amagova, V.Kh. Matsadze Advances of modern science, 2, 9 (2017).

[5] Z.A. Amagova, N.A. Golubkina, V.Kh. Matsadze, Biogeochemistry - the scientific basis of steady development and maintenance of human health, Papers of the XI International Biogeochemical school, 72-76 (2019).

[6] O.A. Senkevitch, N.A. Golubkina, Yu.G. Kovalskiy, Z.V. Sirotina, G.V. Iskrenok, D.S. Beldy, Far East Medicinal Journal, 82-84 (2009).

[7] N.A. Golubkina, Yu.G. Kovalskiy, I.Yu. Tarmaeva, O.A. Senkevitch, Biogeochemistry the scientific basis of steady development and maintenance of human health, Papers of the XI International Biogeochemical school, 32-36 (2019).

[8] V.V. Borisov, Consilium medicum, 20, 7 (2018).

[9] E.V. Brezhneva, V.M. Ivoylov, S.F. Zinchuk, T.A. Shternis, Medicine in Kusbass, 5 (2003).

[10] E.V. Brezhneva, S.F. Zinchuk, Federal and regional policy in the sphere of healthy nutrition, The International Symposium Papers (2002).

[11] V.I. Pankiv, International Journal of Endocrinology, 5, 75-80, (2014).

[12] L.L. Zubkova, Bulletin of the Buryat State University, 12, 101-104 (2009).

[13] D. Bebne, C. Weiss-Nowak, M. Kaikloscb, et al. Analyst, 120, 823-825 (1995).

[14] R.L. Lander, T. Enkhjargal, J. Batjargal, et al., Asia Pacific J. Clin. Nutr., 17, 429-440 (2008).

[15] S.B. Garmaeva, L.A. Reshetnik, Micro-elements in medicine, 13, 3 (2012).

[16] Y.I. Kirova, Cand. biol. sc., 186 (2004).

[17] V.A. Baraboy, Advances of modern biology, 124, 2 (2004).

[18] J. Luo, D. Qi, Y. Zheng, J. Mu, G. Yan, T. Yang, J. Shen, FEBS Lett, 449 (2001).

[19] L.A. Mayurnikova, S.D. Rudnev, N.I. Davydenko, S.V. Novoselov, D.G. Popova, Foods and Raw Materials, 6, 1 (2018).

[20] I.V. Gmoshinskiy, V.K. Mazo, Issues of nutrition, 75, 5 (2006).

[21] J.C. Allen, J. Dairy Sci., 63, 4 (1980). 
[22] M.A. Grum-Grzhimaylo, N.A. Golubkina, Beer and beverages, 2, 37-43 (1997).

[23] Grocery raw materials and food products, Voltammetric method for measuring mass concentration of selenium: Technical tips, 08-47 (2003).

[24] Y.M. Kulagina, I.F. Golovatskaya, Bulletin of Tomsk State University, Biology, 2, 56-64 (2011).

[25] I.F. Golovatskaya, A.V. Krachaleva, Tomsk State Pedagogical University Bulletin, I 8, 85-88 (2011).

[26] E.V. Shigina, Development and commodity assessment of the functional drink based on plant raw materials fortified with selenium: diss. cand. Tech. (2005).

[27] M.B. Maria, G.Y. Enrique, Anal. chem., 74, 107113 (2002).

[28] N.I. Davydenko, L.A. Mayurnikova, Foods and Raw Materials, 2, 1 (2014). 